\title{
Perioperative blood transfusion has distinct postsurgical oncologic impact on patients with different stage of hepatocellular carcinoma
}

Gui-Xing Chen ${ }^{1+}$, Chao-Ying $\mathrm{Qi}^{2 \dagger}$, Wen-Jie Hu${ }^{1}$, Xiao-Hui Wang ${ }^{1}$, Yun-Peng Hua ${ }^{1}$, Ming Kuang ${ }^{1}$, Bao-Gang Peng ${ }^{1}$ and Shao-Qiang $\mathrm{Li}^{1 *}$

\begin{abstract}
Background: The influence of perioperative blood transfusion (PBT) on postsurgical survival of patients with different stage of hepatocellular carcinoma (HCC) is not well clarified. This study aimed to evaluate the impact of PBT on survival outcomes of different stage of HCC patients.

Methods: Consecutive patients who underwent liver resection for HCC between January 2009 and November 2015 were identified from an HCC prospective database in authors' center. The survival outcomes were compared between patients receiving PBT and those without PBT before and after propensity score matching (PSM) in different stage subsets. Cox regression analysis was performed to verify the impact of PBT on outcomes of HCC.

Results: Among 1255 patients included, 804 (64.1\%) were Barcelona Clinic Liver Cancer (BCLC) stage 0-A, and 347 (27.6\%) received PBT. Before PSM, patients with PBT had worse disease free survival (DFS) and overall survival (OS) compared with those without PBT in both BCLC 0-A subset and BCLC B-C subset (all $P<0.05$ ). After PSM, 288 pairs of patients (with and without PBT) were created. In the subset of BCLC 0-A, the median DFS of patients with PBT was shorter than those without PBT (12.0 months vs. 36.0 months, $P=0.001)$ Similar result was observed for OS (36.0 months vs. 96.0 months, $P=0.001$ ). In the subset of BCLC B-C, both DFS and OS were comparable between patients with $\mathrm{PBT}$ and those without $\mathrm{PBT}$. Cox regression analysis showed that PBT involved an increasing risk of DFS $(H R=1.607 ; P<0.001)$ and OS $(H R=1.756 ; P<0.001)$ for this subset. However, PBT had no impact on DFS $(P=$ $0.126)$ or OS $(P=0.139)$ for those with stage B-C HCC.
\end{abstract}

Conclusions: PBT negatively influenced oncologic outcomes of patient with BCLC stage 0-A HCC, but not those with stage B-C after curative resection.

Keywords: Hepatocellular carcinoma, Blood transfusion, Outcomes, Hepatectomy

\footnotetext{
* Correspondence: lishaoq@mail.sysu.edu.cn

${ }^{\dagger}$ Gui-Xing Chen and Chao-Ying Qi contributed equally to this work.

'Department of Liver Surgery, The First Affiliated Hospital of Sun Yat-sen University, No. 58 Zhongshan Er Road, Guangzhou 510080, China Full list of author information is available at the end of the article
}

(c) The Author(s). 2020 Open Access This article is licensed under a Creative Commons Attribution 4.0 International License, which permits use, sharing, adaptation, distribution and reproduction in any medium or format, as long as you give appropriate credit to the original author(s) and the source, provide a link to the Creative Commons licence, and indicate if changes were made. The images or other third party material in this article are included in the article's Creative Commons licence, unless indicated otherwise in a credit line to the material. If material is not included in the article's Creative Commons licence and your intended use is not permitted by statutory regulation or exceeds the permitted use, you will need to obtain permission directly from the copyright holder. To view a copy of this licence, visit http://creativecommons.org/licenses/by/4.0/. The Creative Commons Public Domain Dedication waiver (http://creativecommons.org/publicdomain/zero/1.0/) applies to the data made available in this article, unless otherwise stated in a credit line to the data. 


\section{Background}

Hepatocellular carcinoma (HCC) is the fifth most common tumor worldwide, and it is the second leading cause of cancer-related death in China [1]. Liver resection is the mainstay curative treatment for early-stage $\mathrm{HCC}$ and selected intermediate-stage or advanced-stage $\mathrm{HCC}$ with preserved liver function [2]. As the resection technique and perioperative management have improved, surgical morbidity and mortality following hepatectomy have substantially decreased $[3,4]$. In particular, refined surgical manipulation involves reduced blood loss during liver resection; however, liver resection for HCC involves a high risk of bleeding due to underlying cirrhosis. The blood transfusion rate during liver resection has decreased from 66 to $22 \%$ in the past two decades [5].

Blood transfusion is still a life-saving therapy when excessive intraoperative bleeding occurs, but it involves the risk of transfusion-related complications, such as transmission of hepatitis viruses, human immunodeficiency virus, and allergic reactions [6]. Regarding oncologic outcomes, although many studies had been reported, the influence of perioperative blood transfusion (PBT) on postoperative survival outcomes is controversial [7-12]. Furthermore, the influence of PBT on different stage of resectable $\mathrm{HCC}$ has not been well investigated.

In this study, we focused on the impact of PBT on oncologic outcomes of patient with different stage of HCC after curative resection by using propensity score matching (PSM) analysis and Cox regression analysis.

\section{Methods}

\section{Patients}

From January 2009 to November 2015, all consecutive patients with HCC undergoing curative liver resection (complete resection of gross tumors with a pathological tumor free margin) in the authors' department were evaluated for this study. Clinical data were entered prospectively in an HCC database and reviewed retrospectively. Patients with $\mathrm{HCC}$ with bile duct tumor thrombus or ruptured HCC treated with hepatectomy, those who died within 30 days postoperatively (surgical mortality) were excluded. This study was approved by the ethics committee of The First Affiliated Hospital of Sun Yat-sen University, and written informed consent was obtained from all patients.

\section{Perioperative assessment}

Preoperative evaluation of and resection criteria for HCC at our center were previously described [13]. The treatment option was decided by the HCC multidisciplinary team. The Barcelona Clinic Liver Cancer (BCLC) staging system was used for HCC staging [14]. Although we used the Child-Pugh score to evaluate liver function in clinical practice in this cohort of patients, we used albumin to bilirubin (ALBI) scores for data analysis because it was reported that they are more accurate and objective than conventional Child-Pugh scores $[15,16]$. The neutrophil-to-lymphocyte ratio (NLR) was obtained by dividing the neutrophil count by the lymphocyte count. The platelet-to-lymphocyte ratio (PLR) referred to the platelet count subtracted from the lymphocyte count. The alanine transaminase (ALT)-to-platelet ratio index (APRI) was calculated as follows: [ALT $\div$ (upper limit of ALT $\times$ platelet count) $\times 100$. These inflammatory parameters were transformed to binary variables in the Cox regression analysis by using their median values as the cutoff thresholds, respectively.

PBT referred to the transfusion of packed red blood cells (RBCs) during excessive intraoperative bleeding or postoperative bleeding complications. Transfusions of platelets, fresh-frozen plasma, and albumin were not included. The PBT criteria were preoperative anemia (hemoglobin $\leq 70 \mathrm{~g} / \mathrm{L}$ ) and excessive intraoperative or postoperative intra-abdominal bleeding with unstable hemodynamics or hemoglobin $<70 \mathrm{~g} / \mathrm{L}$. Postoperative complications were graded by the Clavien-Dindo classification [17].

\section{Surgical procedures}

Liver resection included anatomical resection (AR) and non-anatomical resection (NAR), which was introduced in our previous report [13]. Briefly, AR was planned for central tumors, tumors with ipsilateral satellite nodules, or portal vein tumor thrombus (PVTT), and for patients with a sufficient liver remnant after AR. NAR was preferred for peripheral tumors and for patients with an insufficient liver remnant after AR was performed. The Pringle maneuver was applied if necessary. Major resection was defined as resection larger than three segments.

\section{Propensity score matching analysis}

To minimize the influence of patient selection bias and confounding variables between groups in this retrospective study, a PSM analysis was used $[18,19]$. In this study, four levels of outcome-related variables, including patient and underlying liver disease-related [age, sex, preoperative hemoglobin level, platelet count, positive HBsAg, cirrhosis, prothrombin time (PT), alanine transaminase (ALT) level, ALBI grade], tumor-related [tumor size, tumor number, tumor capsule, microvascular invasion (MVI), portal vein tumor thrombus (PVTT), hepatic vein tumor thrombus (HVTT), alpha fetoprotein (AFP) level, tumor differentiation], systemic inflammation - related (NLR, PLR, APRI), and procedure-related variables (extent of resection, resection type, resection margin, and Pringle maneuver), were included in the propensity score model to balance the baseline of groups as much 
Table 1 Baseline characteristics of patients with PBT and those without PBT in different HCC stage subset in the entire cohort $(n=$ 1255)

\begin{tabular}{|c|c|c|c|c|c|c|}
\hline \multirow[t]{2}{*}{ Variable } & \multicolumn{3}{|l|}{ BCLC 0-A $(n=804)$} & \multicolumn{3}{|l|}{ BCLC B-C $(n=451)$} \\
\hline & $\begin{array}{l}\text { PBT } \\
n=171)\end{array}$ & $\begin{array}{l}\text { Non-PBT } \\
(n=633)\end{array}$ & $P$-value & $\begin{array}{l}\text { PBT } \\
(n=176)\end{array}$ & $\begin{array}{l}\text { Non-PBT } \\
(n=275)\end{array}$ & $P$-value \\
\hline \multicolumn{7}{|c|}{ Demographic factors } \\
\hline Age, yr & $52.9 \pm 12.5$ & $50.9 \pm 12.1$ & 0.062 & $49.9 \pm 12.2$ & $49.1 \pm 12.5$ & 0.544 \\
\hline \multicolumn{7}{|l|}{ Sex, n (\%) } \\
\hline Male & $139(81.3)$ & $557(88.0)$ & 0.220 & $157(89.2)$ & $249(90.5)$ & 0.644 \\
\hline Female & $32(18.7)$ & $76(12.0)$ & & $19(10.8)$ & $26(9.5)$ & \\
\hline \multicolumn{7}{|l|}{ HBsAg, n (\%) } \\
\hline Positive & $143(83.6)$ & $545(86.1)$ & 0.415 & $148(84.1)$ & $228(82.9)$ & 0.743 \\
\hline Negative & $28(16.4)$ & $88(13.9)$ & & $28(15.9)$ & $47(17.1)$ & \\
\hline \multicolumn{7}{|l|}{ Cirrhosis, n (\%) } \\
\hline Yes & $123(71.9)$ & $427(67.5)$ & 0.265 & $133(75.6)$ & $198(72)$ & 0.404 \\
\hline No & $48(28.1)$ & $206(32.5)$ & & $43(24.4)$ & $77(28)$ & \\
\hline Hemoglobin, g/L & $129.7 \pm 22.8$ & $141.6 \pm 17.5$ & $<0.001$ & $131.2 \pm 23.1$ & $140.3 \pm 19.9$ & 0.000 \\
\hline Platelet count, $\times 10^{9} / \mathrm{L}$ & $185.0 \pm 64.5$ & $201.3 \pm 92.9$ & 0.008 & $215.4 \pm 113.3$ & $207.1 \pm 71.3$ & 0.338 \\
\hline Prothrombin time, s & $13.0 \pm 1.6$ & $12.7 \pm 0.9$ & 0.001 & $13.1 \pm 1.1$ & $12.7 \pm 1.3$ & 0.001 \\
\hline ALT, U/L, median (range) & $39(6565)$ & $33(71428)$ & 0.024 & $42.5(8237)$ & $38.0(6522)$ & 0.189 \\
\hline \multicolumn{7}{|l|}{ ALBI grade, $n(\%)$} \\
\hline Grade 1 & $84(49.1)$ & $399(63.0)$ & $<0.001$ & $76(43.2)$ & $160(58.2)$ & 0.001 \\
\hline Grade 2 & $84(49.1)$ & $232(36.7)$ & & $99(56.3)$ & $115(41.8)$ & \\
\hline Grade 3 & $3(1.8)$ & $2(0.3)$ & & $1(0.5)$ & 0 & \\
\hline \multicolumn{7}{|l|}{ Inflammatory factors } \\
\hline NLR, median (range) & $2.4(0.5,13.0)$ & $1.9(0.3,24.9)$ & $<0.001$ & $2.5(0.9,24.4)$ & $2.3(0.6,18.3)$ & 0.013 \\
\hline PLR, median (range) & $121.1(21.61432 .1)$ & $96.9(19.4414 .0)$ & $<0.001$ & $133.9(19.8751 .0)$ & $119.6(20.6314 .6)$ & $<0.001$ \\
\hline APRI, median (range) & $0.6(0.1,12.2)$ & $0.5(0.1,21.1)$ & 0.038 & $0.6(0.1,3.8)$ & $0.5(0.1,5.7)$ & 0.079 \\
\hline \multicolumn{7}{|l|}{ Tumor characteristics } \\
\hline \multicolumn{7}{|l|}{ AFP, ug/L } \\
\hline$\geq 400$ & $99(42.1)$ & $214(33.8)$ & 0.044 & $88(50)$ & $149(54.2)$ & 0.387 \\
\hline$<400$ & $72(57.9)$ & $419(66.2)$ & & $88(50)$ & $126(45.8)$ & \\
\hline Tumor size, $\mathrm{cm}$ & $9.2 \pm 6.1$ & $6.2 \pm 3.1$ & $<0.001$ & $10.7 \pm 3.92$ & $8.9 \pm 3.5$ & $<0.001$ \\
\hline \multicolumn{7}{|l|}{ Tumor number, n (\%) } \\
\hline Solitary & $167(97.7)$ & $596(94.2)$ & 0.049 & $59(33.5)$ & $87(31.6)$ & 0.975 \\
\hline 2 & $4(2.3)$ & $29(4.6)$ & & $59(33.5)$ & $102(37.1)$ & \\
\hline 3 & $0(0)$ & $8(1.2)$ & & $18(10.2)$ & $25(9.1)$ & \\
\hline 4 & $0(0)$ & $0(0)$ & & $40(22.8)$ & $61(22.2)$ & \\
\hline \multicolumn{7}{|l|}{ Tumor capsule, n (\%) } \\
\hline Complete & $137(80.1)$ & $574(90.7)$ & $<0.001$ & $107(60.8)$ & $187(68)$ & 0.118 \\
\hline Incomplete & $34(19.9)$ & $59(9.3)$ & & $69(39.2)$ & $88(32)$ & \\
\hline \multicolumn{7}{|l|}{ Differentiation, n (\%) } \\
\hline $1+\|$ & $115(67.3)$ & $465(73.5)$ & 0.108 & $119(67.6)$ & $193(70.2)$ & 0.566 \\
\hline III, IV & $56(32.7)$ & $168(26.5)$ & & $57(32.4)$ & $82(29.8)$ & \\
\hline \multicolumn{7}{|l|}{ MVI, n (\%) } \\
\hline Yes & $50(29.2)$ & $123(19.4)$ & 0.006 & $79(44.9)$ & $105(38.2)$ & 0.158 \\
\hline No & $121(70.8)$ & $510(80.6)$ & & $97(55.1)$ & $170(61.8)$ & \\
\hline \multicolumn{7}{|l|}{ PVTT, n (\%) } \\
\hline Yes & 0 & 0 & & $100(56.8)$ & $116(42.2)$ & 0.002 \\
\hline No & $171(100)$ & $633(100)$ & & $76(43.2)$ & $159(57.8)$ & \\
\hline
\end{tabular}


Table 1 Baseline characteristics of patients with PBT and those without PBT in different HCC stage subset in the entire cohort $(n=$ 1255) (Continued)

\begin{tabular}{|c|c|c|c|c|c|c|}
\hline \multirow[t]{2}{*}{ Variable } & \multicolumn{3}{|l|}{ BCLC 0-A $(n=804)$} & \multicolumn{3}{|l|}{ BCLC B-C $(n=451)$} \\
\hline & $\begin{array}{l}\text { PBT } \\
n=171)\end{array}$ & $\begin{array}{l}\text { Non-PBT } \\
(n=633)\end{array}$ & $P$-value & $\begin{array}{l}\text { PBT } \\
(n=176)\end{array}$ & $\begin{array}{l}\text { Non-PBT } \\
(n=275)\end{array}$ & $P$-value \\
\hline HVTT, n (\%) & & & & & & 0.000 \\
\hline Yes & 0 & 0 & & $21(11.9)$ & $7(2.5)$ & \\
\hline No & $171(100)$ & $633(100)$ & & $155(88.1)$ & $268(97.5)$ & \\
\hline \multicolumn{7}{|l|}{ Surgical factors } \\
\hline \multicolumn{7}{|l|}{ Extent of resection, n (\%) } \\
\hline Major & $64(37.4)$ & $194(30.6)$ & 0.092 & $126(71.6)$ & $180(65.5)$ & 0.174 \\
\hline Minor & $107(62.6)$ & $439(69.4)$ & & $50(28.4)$ & $95(34.5)$ & \\
\hline \multicolumn{7}{|l|}{ Type of resection, n (\%) } \\
\hline Anatomical & $62(36.3)$ & $203(32.1)$ & 0.302 & $97(55.1)$ & $150(54.5)$ & 0.906 \\
\hline Nonanatomical & $109(63.7)$ & $430(67.9)$ & & $79(44.9)$ & $125(45.5)$ & \\
\hline \multicolumn{7}{|l|}{ Resection margin } \\
\hline$\leq 1 \mathrm{~cm}$ & $32(18.7)$ & $58(9.2)$ & $<0.001$ & $56(31.8)$ & $122(44.4)$ & 0.008 \\
\hline$>1 \mathrm{~cm}$ & $139(81.3)$ & $575(90.8)$ & & $120(68.2)$ & $153(55.6)$ & \\
\hline \multicolumn{7}{|l|}{ Pringle maneuver, n (\%) } \\
\hline Yes & $111(64.9)$ & $380(60.0)$ & 0.245 & $114(64.8)$ & $169(61.4)$ & 0.477 \\
\hline No & $60(35.1)$ & $253(40.0)$ & & $62(35.2)$ & $106(38.6)$ & \\
\hline Blood loss, ml, median (range) & $1484.7(200,12,000)$ & $200(50,3000)$ & $<0.001$ & $1000(200,10,500)$ & $300(30,2500)$ & $<0.001$ \\
\hline \multicolumn{7}{|l|}{ Clavien-Dindo grade } \\
\hline I & $4(2.3)$ & $9(1.4)$ & 0.045 & $3(1.7)$ & $8(2.9)$ & 0.950 \\
\hline$\|$ & $1(0.6)$ & $9(1.4)$ & & $2(1.1)$ & $4(1.5)$ & \\
\hline III & $15(8.8)$ & $31(4.9)$ & & $10(5.7)$ & $18(6.5)$ & \\
\hline IV & $2(1.2)$ & $3(0.5)$ & & $3(1.7)$ & $2(0.7)$ & \\
\hline
\end{tabular}

Abbreviation: $H B s A g$ Hepatitis B surface antigen, $A B L /$ grade albumin to bilirubin grade, $A L T$ anlanine transaminase, NLR neutrophil to lymphocyte ratio, $P L R$ platelet to lymphocyte ratio, APRI alanine transaminase to platelet ratio index, PVTT portal vein tumor thrombus, HVTT hepatic vein tumor thrombus, MVI microscopic vascular invasion, AFP alpha fetoprotein

as possible. PSM was performed using $\mathrm{R}$ software $(\mathrm{R}$ 2.15.3; http://www.r-project.org). A one-to-one nearest neighbor matching without replacement algorithm was applied. To obtain the best trade-off between homogeneity and retained sample size, caliper widths of 0.20 , $0.10,0.050$, and 0.010 were tested in our cohort of patients. We found that a caliper width of 0.1 met the requirement.

\section{Follow-up}

The follow-up protocols for $\mathrm{HCC}$ and treatment of recurrent $\mathrm{HCC}$ at our center were described previously [13]. The main outcomes of this study were disease free survival (DFS) and overall survival (OS). DFS was calculated from the date of tumor resection to the date of first tumor recurrence or the last follow-up visit. The OS was calculated from the date of tumor resection to the date of death or the date of the last follow-up visit. The endpoint follow-up was December 30, 2016. The median follow-up period was 51.0 months (range, 3-102 months). The treatments of recurrent $\mathrm{HCC}$ including radiofrequency ablation, re- hepatectomy, transarterial chemoembolization, or sorafenib alone or combined therapy based on the number, location of recurrent tumor and liver function reserve.

\section{Statistical analysis}

The clinical database was established using SPSS for Windows (version 22.0; IBM, Armonk, NY, USA). Continuous data are expressed as mean (standard deviation) or median (range). The independent $t$ test or MannWhitney $U$ test was used to compare continuous data between groups, and the $\chi^{2}$ test was used for discrete data. Cumulative DFS and OS rates were calculated using the Kaplan-Meier method and compared between groups using the log rank test. A Cox regression model involving univariable and multivariable analyses was used to identify risk factors associated with DFS and OS. All factors with statistical significance $(P<0.05)$ in the univariable analysis were entered into the multivariable analysis (forward method) to yield independent risk factors. $P<0.05$ was considered statistically significant. 
A

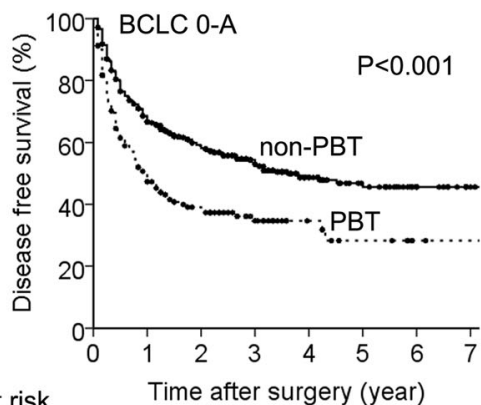

No. at risk

non-PBT $63340626816265 \quad 38 \quad 23 \quad 10$

PBT $\begin{array}{llllllll}171 & 75 & 43 & 23 & 12 & 6 & 2 & 1\end{array}$

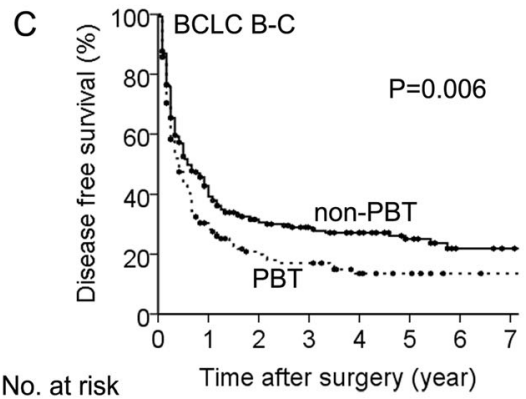

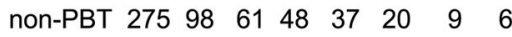

PBT $\begin{array}{llllllll}176 & 41 & 21 & 18 & 9 & 5 & 2 & 1\end{array}$
B

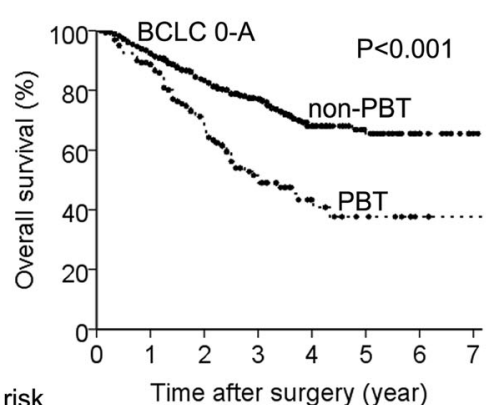

No. at risk

non-PBT $\begin{array}{llllllll}633 & 546 & 377 & 242 & 95 & 49 & 27 & 13\end{array}$

$\begin{array}{lllllllll}\text { PBT } & 171 & 132 & 81 & 40 & 17 & 9 & 3 & 1\end{array}$

D

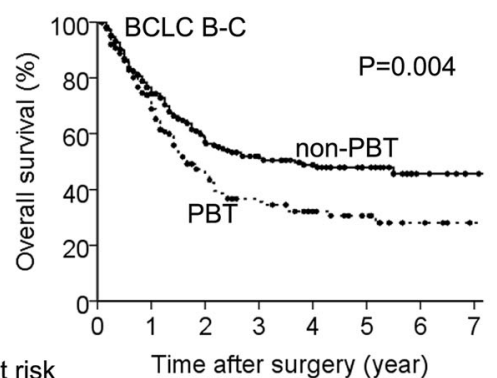

No. at risk

Time after surgery (year)

non-PBT $275 \begin{array}{lllllll}2765 & 102 & 70 & 55 & 30 & 12 & 7\end{array}$

PBT $\begin{array}{llllllll}176 & 100 & 48 & 33 & 22 & 15 & 7 & 3\end{array}$

Fig. 1 Survival curves of patients with PBT and without PBT in the BCLC 0-A subset and the BCLC B-C subset in the entire cohort. a DFS in the BCLC 0-A subset. $\mathbf{b}$ OS in the BCLC 0-A subset. $\mathbf{c}$ DFS in the BCLC B-C subset. $\mathbf{d}$ OS in the BCLC B-C subset (Log rank test)

\section{Results}

A total of 1336 patients had surgery for HCC in this study period. Eighty-one patients were excluded from this study: 17 patients with bile duct tumor thrombus; 53 patients with rupture HCC; and $11(0.9 \%, 11 / 1266)$ patients who died of postoperative liver failure. Finally, 1255 patients who underwent liver resection with curative intent were recruited in this study. Most patients (84.8\%) had underlying HBV infection. 27.6\% (347/1255) received $\mathrm{PBT}$. The patients were classified into two subsets: the BCLC 0-A subset $(n=804,64.1 \%)$ and the BCLC B-C subset $(n=451,35.9 \%)$ according to tumor stage.

\section{Patients' clinicopathologic features in the entire cohort}

The baseline clinical data of patients with PBT and those without PBT (non-PBT) within the BCLC 0-A subset and the BCLC B-C subset were compared respectively and summarized in Table 1 . Numerous variables were significantly different between patients with PBT and those without PBT within each subset. $21.3 \%(171 / 804)$ of patients received PBT in the subset of BCLC 0-A, and 39.0\% (176/451) in the BCLC $\mathrm{B}-\mathrm{C}$ subset.

\section{Survival impact of PBT on different stages of HCC in the entire cohort}

In the subset of BCLC 0-A, the median DFS was 12.0 months (95\% confidence interval [CI]: 7.9-16.1) for PBT group and 43.1 months (95\% CI: 28.5-57.8) for the nonPBT group $(P<0.001)$ (Fig. 1a). The median OS was 36.0 months (95\%CI: 25.0-47.0) for the PBT group and 96.0 months for the non-PBT group $(P<0.001)$ (Fig. 1b). In the subset of BCLC B-C, the median DFS was 5.0 months (95\% CI: 3.8-6.2) for PBT group and 7.0 months (95\% CI: 4.6-9.4) for the non-PBT group $(P=0.006)$ (Fig. 1c). The median OS was 20.0 months $(95 \% \mathrm{CI}$ : 14.5-25.5) for the PBT group and 44.0 months for the non-PBT group $(P=0.004)$ (Fig. 1d).

\section{Propensity score matching analysis}

Because numerous variables were different between the PBT group and the non-PBT group in each subset of patients, a large patient selection bias existed for the entire cohort. To overcome this selection bias, PSM was used. Twenty-four variables, including patient and underlying liver disease-related, tumor-related, systemic inflammation-related, and procedure-related factors were selected as the matched factors and entered in the PSM model. After matching, 288 pairs of patients were 
Table 2 Baseline characteristics of patients with PBT and those without PBT in different HCC stage subset in the matched cohort $(n=576)$

\begin{tabular}{|c|c|c|c|c|c|c|}
\hline \multirow[t]{2}{*}{ Variable } & \multicolumn{3}{|l|}{ BCLC 0-A $(n=317)$} & \multicolumn{3}{|l|}{ BCLC B-C $(n=259)$} \\
\hline & $\begin{array}{l}\text { PBT } \\
n=156)\end{array}$ & $\begin{array}{l}\text { Non-PBT } \\
(n=161)\end{array}$ & $P$-value & $\begin{array}{l}\text { PBT } \\
(n=132)\end{array}$ & $\begin{array}{l}\text { Non-PBT } \\
(n=127)\end{array}$ & $P$-value \\
\hline \multicolumn{7}{|l|}{ Demographic factors } \\
\hline Age, yr & $52.7 \pm 12.3$ & $53.1 \pm 12.4$ & 0.787 & $49.2 \pm 12.6$ & $51.4 \pm 13.1$ & 0.182 \\
\hline \multicolumn{7}{|l|}{ Sex, n (\%) } \\
\hline Male & $127(81.4)$ & $126(78.3)$ & 0.487 & $118(89.4)$ & $115(90.6)$ & 0.758 \\
\hline Female & $29(18.6)$ & $35(21.7)$ & & $14(10.6)$ & $12(9.4)$ & \\
\hline \multicolumn{7}{|l|}{ HBsAg, n (\%) } \\
\hline Positive & $132(84.6)$ & $138(85.7)$ & 0.784 & $112(84.8)$ & $103(81.1)$ & 0.424 \\
\hline Negative & $24(15.4)$ & $23(14.3)$ & & $20(15.2)$ & $24(18.9)$ & \\
\hline \multicolumn{7}{|l|}{ Cirrhosis, n (\%) } \\
\hline Yes & $144(73.1)$ & $121(75.2)$ & 0.674 & $101(76.5)$ & $93(73.2)$ & 0.544 \\
\hline No & $42(26.9)$ & $40(24.8)$ & & $31(23.5)$ & $34(26.8)$ & \\
\hline Hemoglobin, g/L & $132.0 \pm 21.5$ & $133.4 \pm 19.8$ & 0.548 & $136.3 \pm 21.1$ & $133.4 \pm 19.4$ & 0.245 \\
\hline Platelet count, $\times 10^{9} / \mathrm{L}$ & $201.8 \pm 93.3$ & $180.6 \pm 71.3$ & 0.023 & $197.8 \pm 85.0$ & $207.9 \pm 73.4$ & 0.307 \\
\hline Prothrombin time, s & $12.9 \pm 1.6$ & $12.9 \pm 0.1$ & 0.705 & $13.0 \pm 1.1$ & $13.0 \pm 1.1$ & 0.894 \\
\hline ALT, U/L, median (range) & $38(6293)$ & $34(71428)$ & 0.931 & $44(8,237)$ & $38(12,522)$ & 0.541 \\
\hline \multicolumn{7}{|l|}{ ALBI grade, $n(\%)$} \\
\hline Grade 1 & $82(52.5)$ & $77(47.8)$ & 0.486 & $64(48.4)$ & $53(41.7)$ & 0.341 \\
\hline Grade 2 & $72(46.2)$ & $83(51.6)$ & & $67(50.8)$ & $74(58.3)$ & \\
\hline Grade 3 & $2(1.3)$ & $1(0.6)$ & & $1(0.8)$ & 0 & \\
\hline \multicolumn{7}{|l|}{ Inflammatory factors } \\
\hline NLR, median (range) & $2.2(0.52,13.03)$ & $2.1(0.3,24.9)$ & 0.904 & $2.3(0.9,24.4)$ & $2.5(1.1,15.8)$ & 0.901 \\
\hline PLR, median (range) & $117.8(21.4,405.4)$ & $107.8(19.4,414.0)$ & 0.379 & $118.4(19.8,460.3)$ & $131.1(20.6,314.6)$ & 0.440 \\
\hline APRI, median (range) & $0.5(0.1,5.3)$ & $0.5(0.1,21.1)$ & 0.621 & $0.6(0.1,3.8)$ & $0.5(0.1,5.7)$ & 0.269 \\
\hline \multicolumn{7}{|l|}{ Tumor characteristics } \\
\hline \multicolumn{7}{|l|}{ AFP, ug/L } \\
\hline$\geq 400$ & $64(41.0)$ & $60(37.3)$ & 0.493 & $61(46.2)$ & $70(55.1)$ & 0.153 \\
\hline$<400$ & $92(59.0)$ & $101(68.9)$ & & $71(53.8)$ & $57(44.9)$ & \\
\hline Tumor size, $\mathrm{cm}$ & $8.4 \pm 4.4$ & $7.69 \pm 3.86$ & 0.110 & $9.8 \pm 3.5$ & $10.1 \pm 3.5$ & 0.441 \\
\hline \multicolumn{7}{|l|}{ Tumor number, n (\%) } \\
\hline Solitary & $153(98.1)$ & $156(96.7)$ & 0.502 & $38(28.8)$ & $45(35.4)$ & 0.524 \\
\hline 2 & $3(1.9)$ & $5(3.1)$ & & $48(36.4)$ & $45(35.4)$ & \\
\hline 3 & 0 & 0 & & $16(12.1)$ & $4(3.2)$ & \\
\hline 4 & 0 & 0 & & $30(22.7)$ & $33(26.0)$ & \\
\hline \multicolumn{7}{|l|}{ Tumor capsule, n (\%) } \\
\hline Complete & $127(81.4)$ & $135(83.9)$ & 0.568 & $86(65.2)$ & $81(63.8)$ & 0.818 \\
\hline Incomplete & $29(18.6)$ & $26(16.1)$ & & $46(34.8)$ & $46(36.2)$ & \\
\hline \multicolumn{7}{|l|}{ Differentiation, n (\%) } \\
\hline $1+\|$ & $108(69.2)$ & $111(68.9)$ & 0.956 & $88(66.7)$ & $85(66.9)$ & 0.964 \\
\hline III, IV & $48(30.8)$ & $50(16.1)$ & & $44(33.3)$ & $42(33.1)$ & \\
\hline \multicolumn{7}{|l|}{ MVI, n (\%) } \\
\hline Yes & $35(22.4)$ & $33(20.5)$ & 0.674 & $62(47.0)$ & $66(52.0)$ & 0.196 \\
\hline No & $121(77.6)$ & $128(79.5)$ & & $70(53.0)$ & $61(48.0)$ & \\
\hline \multicolumn{7}{|l|}{ PVTT, n (\%) } \\
\hline Yes & 0 & 0 & & $68(51.5)$ & $72(56.7)$ & 0.405 \\
\hline No & $156(100)$ & $161(100)$ & & $64(48.5)$ & $55(43.3)$ & \\
\hline
\end{tabular}


Table 2 Baseline characteristics of patients with PBT and those without PBT in different HCC stage subset in the matched cohort $(n=576)$ (Continued)

\begin{tabular}{|c|c|c|c|c|c|c|}
\hline \multirow[t]{2}{*}{ Variable } & \multicolumn{3}{|l|}{ BCLC 0-A $(n=317)$} & \multicolumn{3}{|c|}{ BCLC B-C $(n=259)$} \\
\hline & $\begin{array}{l}\text { PBT } \\
n=156)\end{array}$ & $\begin{array}{l}\text { Non-PBT } \\
(n=161)\end{array}$ & $P$-value & $\begin{array}{l}\text { PBT } \\
(n=132)\end{array}$ & $\begin{array}{l}\text { Non-PBT } \\
(n=127)\end{array}$ & $P$-value \\
\hline \multicolumn{7}{|l|}{ HVTT } \\
\hline Yes & 0 & 0 & & $9(6.8)$ & $5(3.9)$ & 0.307 \\
\hline No & $156(100)$ & $161(100)$ & & $123(93.2)$ & $122(96.1)$ & \\
\hline \multicolumn{7}{|l|}{ Surgical factors } \\
\hline \multicolumn{7}{|l|}{ Extent of resection, $n(\%)$} \\
\hline Major & $59(37.8)$ & $58(36.0)$ & 0.741 & $91(68.9)$ & $83(65.4)$ & 0.541 \\
\hline Minor & $97(62.2)$ & $103(64.0)$ & & $41(31.1)$ & $44(34.6)$ & \\
\hline \multicolumn{7}{|l|}{ Type of resection, n (\%) } \\
\hline Anatomical & $55(35.3)$ & $53(32.9)$ & 0.662 & $68(51.5)$ & $69(54.3)$ & 0.651 \\
\hline nonanatomical & $101(64.7)$ & $108(67.1)$ & & $64(48.5)$ & $58(45.7)$ & \\
\hline \multicolumn{7}{|l|}{ Resection margin, cm } \\
\hline$\leq 1$ & $51(32.7)$ & $45(28.0)$ & 0.358 & $99(75.0)$ & $100(78.7)$ & 0.476 \\
\hline$>1$ & $105(67.3)$ & $116(72.0)$ & & $33(25.0)$ & $27(21.3)$ & \\
\hline \multicolumn{7}{|l|}{ Pringle maneuver, n (\%) } \\
\hline Yes & $56(35.9)$ & $46(28.6)$ & 0.163 & $100(75.7)$ & $98(77.2)$ & 0.790 \\
\hline No & $100(64.1)$ & $115(71.4)$ & & $32(24.3)$ & $29(22.7)$ & \\
\hline Blood loss, ml, median (range) & $1000(50,12,000)$ & $200(50,3000)$ & $<0.001$ & $1000(15,7000)$ & $300(50,2500)$ & $<0.001$ \\
\hline \multicolumn{7}{|l|}{ Clavien-Dindo grade ${ }^{a}$} \\
\hline 1 & $3(1.9)$ & $3(1.9)$ & 0.923 & $1(0.8)$ & $4(3.1)$ & 0.689 \\
\hline$\|$ & $1(0.6)$ & $3(1.9)$ & & $1(0.8)$ & $2(1.6)$ & \\
\hline III & $12(7.7)$ & $12(7.5)$ & & $6(4.5)$ & $7(5.5)$ & \\
\hline IV & $2(1.3)$ & $1(0.6)$ & & $2(1.5)$ & $1(0.8)$ & \\
\hline
\end{tabular}

Variables are not included in the matching model

Abbreviation: $A B L I$ grade albumin to bilirubin grade, $A L T$ anlanine transaminase, NLR neutrophil to lymphocyte ratio, $P L R$ platelet to lymphocyte ratio, $A P R I$ alanine transaminase to platelet ratio index, PVTT portal vein tumor thrombus, HVTT hepatic vein tumor thrombus, MVI microscopic vascular invasion, AFP alpha

fetoprotein, PLR platelet to lymphocyte ratio

generated from those with PBT and without PBT. In the matched cohort, apart from blood loss, the confounding variables of the matched groups in each subset were similar (Table 2). The postsurgical complication rates were comparable between patients with $\mathrm{PBT}$ and those without PBT within the BCLC 0-A subset and the BCLC $\mathrm{B}-\mathrm{C}$ subset, respectively.

\section{Survival impact of PBT on different stage of HCC in the matched cohort}

There were 317 (55.0\%) patients with BCLC stage 0-A, and $259(45.0 \%)$ BCLC stage B-C in the matched cohort (Table 2). The median DFS of patients with PBT was significantly shorter than that without PBT in the BCLC stage 0 -A subset (12.0 months [95\%CI, 7.4-16.6] vs. 36.0 months [95\% CI: 10.6-61.4], $P=0.001$, Fig. 2a). Similar result was observed for OS (36.0 months [95\% CI, 23.9-48.0] vs. 96.0 months [95\% CI: $14.6-177.4$ ],$P=$ 0.001, Fig. 2b). However, the median DFS and median OS were comparable between patients with PBT and those without $\mathrm{PBT}$ in the subset of BCLC stage B-C HCC (both $P>0.05$, Fig. 2c, d).

\section{Risk factors affecting DFS and OS}

To further investigate the role of PBT in survival outcomes of HCC, the Cox regression model was used to identify the risk factors associated with DFS and OS of the entire cohort. Twenty-three clinicopathologic variables were included in the univariable analysis (Table 3). The variables with statistical significance $(P<0.05)$ were selected and entered the multivariable analysis (Table 4). The results revealed that PBT had an increased risk of DFS (hazard ratio [HR], 1.607; 95\% CI,1.272-2.031; $P<$ $0.001)$ and $\mathrm{OS}(\mathrm{HR}, 1.756,95 \% \mathrm{CI}, 1.302-2.368 ; P<$ 0.001 ) for patients with stage 0-A HCC after curative resection. However, PBT was not a risk factor of DFS or OS for patients with stage B-C HCC (both $P>0.05$ ).

\section{Discussion}

The impact of PBT on survival outcomes for HCC has been debated for more than two decades [7-12, 20-24]. Because an RCT is impossible on the issue of blood transfusions in clinical practice, all evidences available were based on retrospective study. In 2013, one metaanalysis involved 22 retrospective studies with 5635 


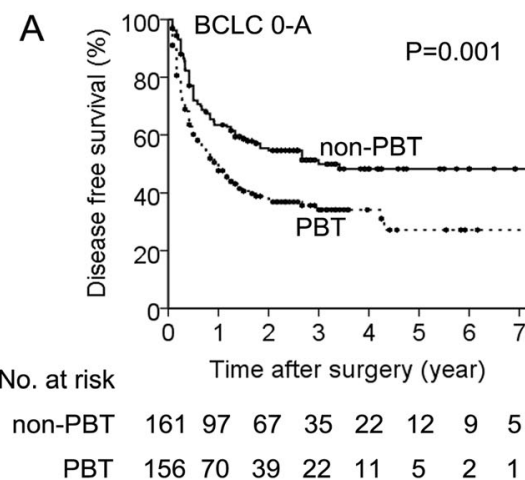

C

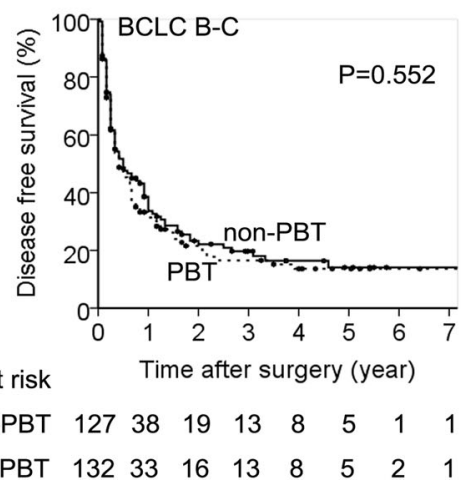

B

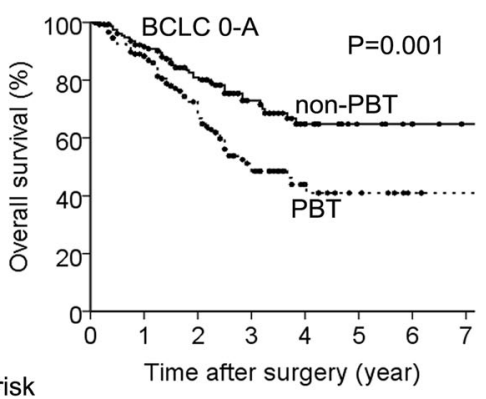

No. at risk

non-PBT $161137 \quad 96 \quad 54 \quad 27 \quad 14 \quad 10 \quad 5$

PBT $156 \begin{array}{lllllll}121 & 75 & 37 & 15 & 8 & 3 & 1\end{array}$

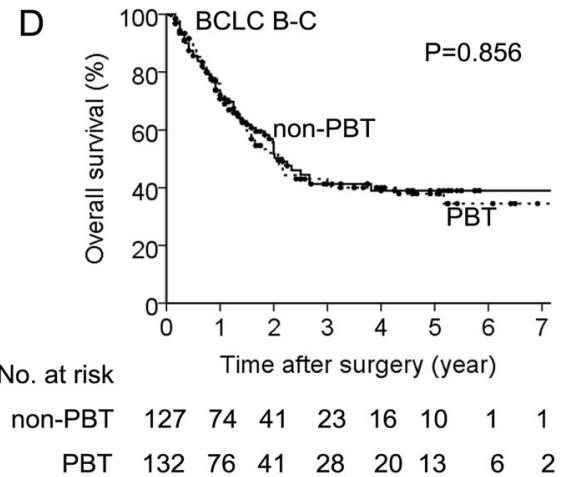

Fig. 2 Survival curves of patients with PBT and without PBT in the BCLC 0-A subset and the BCLC B-C subset in the matched cohort. a DFS in the BCLC 0-A subset. $\mathbf{b}$ OS in the BCLC 0-A subset. $\mathbf{c}$ DFS in the BCLC B-C subset. $\mathbf{d}$ OS in the BCLC B-C subset (Log rank test)

patients concluded that PBT had a negative effect on oncologic outcomes for HCC after resection [12]. However, five studies published recently still yielded controversial conclusions, although they all deliberately used a PSM analysis to adjust patient selection bias [7-11].

Resectable HCC comprised of different stage of disease, from BCLC stage 0 to $\mathrm{C}$, which had large heterogeneity among patients and tumors. The prominent independent risk factors associated with recurrence or OS should be various for different stage of tumor. In the present study, we focused on the impact of PBT on HCC patient with different tumor stage and demonstrated that both DFS and OS for patients with PBT were significantly worse than those without PBT either within the BCLC 0-A subset (Fig. 1a, b) or the BCLC BC subset (Fig. 1c, d) in the entire cohort.

Because the baseline variables of the PBT and nonPBT group within the BCLC 0-A subset or the BCLC B$C$ subset were diverse, patient selection bias largely existed. The patients with PBT had larger tumor burden (i.e., large tumors, multiple tumors, incomplete tumor capsules, PVTT, MVI, high levels of AFP) and higher level of inflammatory indexes (NLR, PLR and APRI) compared with those with non-PBT (Table 1). These are all well-known risk factors associated with tumor recurrence and reduced survival [25-31], as partially confirmed by the present Cox regression analysis (Table 4). This probably explains why the outcomes were worse for the patients with PBT than for those without PBT in the entire cohort.

Therefore, to overcome patient selection bias, PSM that could mimic an RCT study [32] was used. Considering that $\mathrm{HCC}$ recurrence is induced cooperatively by tumor-related, underlying liver disease-related, systemic inflammation-related, and procedure-related factors, the matched variables in the PSM model should comprehensively include these four outcome-related aspects to reduce selection bias as much as possible. Inclusion of more outcome-related variables in PSM would potentially reduce selection bias [33,34]. Notably, there were 24 variables that fully covered the four aspects of risk factors described in our PSM model. The comprehensive inclusion of matched variables would maximally reduce patient selection bias in our study.

Cirrhosis, tumor size, macroscopic venous tumor thrombus and intraopeative blood loss were reported to be the risk factors associated with PBT $[9,11]$. Excessive blood loss is the most important cause of PBT. PBT or blood loss, which one is the prominent factor affecting oncologic outcome is clinically hard to define, although a previous study showed that blood loss predicted recurrence and poor OS [35]. In the present study, Cox 
Table 3 Risk factors associated with postoperative disease free survival and overall survival identified by univariate Cox regression analysis in the entire cohort

\begin{tabular}{|c|c|c|c|c|c|c|}
\hline \multirow[t]{3}{*}{ Variables } & \multicolumn{6}{|l|}{ Univariate Analysis } \\
\hline & \multicolumn{2}{|l|}{ Overall survival } & \multicolumn{4}{|l|}{ Disease-free survival } \\
\hline & Hazard ratio & $p$-valule & Hazard ratio & & & $p$-value \\
\hline \multicolumn{7}{|l|}{ Age, year } \\
\hline$\leq 50$ vs $>50$ & $0.991(0.983-0.999)$ & 0.025 & 0.715 & $(0.617-0.829)$ & & $<0.001$ \\
\hline \multicolumn{7}{|l|}{ Sex } \\
\hline Male vs female & $0.953(0.710-1.278)$ & 0.746 & 0.789 & $(0.622-0.999)$ & & 0.049 \\
\hline \multicolumn{7}{|l|}{ HbsAg } \\
\hline Positive vs negative & $1.013(0.777-1.320)$ & 0.924 & 1.049 & $(0.855-1.288)$ & & 0.646 \\
\hline \multicolumn{7}{|l|}{ Cirrhosis } \\
\hline Yes vs no & $1.230(0.990-1.529)$ & 0.062 & 1.325 & $(1.119-1.568)$ & & 0.001 \\
\hline \multicolumn{7}{|l|}{ ALBI grade } \\
\hline $2+3$ vs 1 & $1.561(1.291-1.886)$ & $<0.0001$ & 1.218 & $(1.052-1.409)$ & & 0.008 \\
\hline \multicolumn{7}{|l|}{ ALT, U/L } \\
\hline$>40$ vs $\leq 40$ & $1.199(0.987-1.457)$ & 0.068 & 1.254 & $(1.082-1.455)$ & & 0.003 \\
\hline \multicolumn{7}{|l|}{ Platelet. $\times 10^{9} / \mathrm{L}$} \\
\hline$\leq 100$ vs $>100$ & $1.007(0.690-1.469)$ & 0.972 & $1.083(0.810-1.448)$ & & & 0.590 \\
\hline \multicolumn{7}{|l|}{ NLR } \\
\hline$>2.3$ vs $\leq 2.3$ & $1.102(1.070-1.134)$ & $<0.001$ & $1.058(1.030-1.087)$ & & & $<0.001$ \\
\hline \multicolumn{7}{|l|}{ PLR } \\
\hline$>118.9$ vs $\leq 118.9$ & $1.002(1.000-1.003)$ & $<0.001$ & 1.002 & $(1.001-1.002)$ & & $<0.001$ \\
\hline \multicolumn{7}{|l|}{ APRI } \\
\hline$>0.55$ vs $\leq 0.55$ & $0.934(0.724-1.206)$ & 0.601 & 1.001 & $(0.847-1.184)$ & & 0.988 \\
\hline \multicolumn{7}{|l|}{ Tumor size, $\mathrm{cm}$} \\
\hline$>5.0$ vs $\leq 5.0$ & $2.353(1.792-3.090)$ & $<0.001$ & $1.832(1.523-2.204)$ & & & $<0.001$ \\
\hline \multicolumn{7}{|l|}{ Tumor number } \\
\hline Multiple vs solitary & $1.906(1.554-2.336)$ & $<0.001$ & 1.768 & $(1.432-2.183)$ & & $<0.001$ \\
\hline \multicolumn{7}{|l|}{ Tumor capsule } \\
\hline Incomplete vs complete & $0.474(0.382-0.588)$ & $<0.001$ & 0.587 & $(0.494-0.698)$ & & $<0.001$ \\
\hline \multicolumn{7}{|l|}{ Differentiation } \\
\hline $3+4$ vs $1+2$ & $1.170(0.948-1.443)$ & 0.145 & 1.183 & $(1.007-1.389)$ & & 0.041 \\
\hline \multicolumn{7}{|l|}{ Macro-VTT } \\
\hline Yes vs no & $3.295(2.660-4.083)$ & $<0.001$ & 2.411 & $(2.026-2.869)$ & & $<0.001$ \\
\hline \multicolumn{7}{|l|}{ MVI } \\
\hline Yes vs no & $2.347(1.925-2.860)$ & $<0.001$ & 1.944 & $(1.664-2.270)$ & & $<0.001$ \\
\hline \multicolumn{7}{|l|}{ AFP, $\mu g / L$} \\
\hline$>400$ vs $\leq 400$ & $1.841(1.516-2.236)$ & $<0.001$ & 1.608 & $(1.386-1.864)$ & & $<0.001$ \\
\hline \multicolumn{7}{|l|}{ Resection margin, $\mathrm{cm}$} \\
\hline$\leq 1.0$ vs $>1.0$ & $1.050(0.998-1.521)$ & 0.354 & $0.865(0.775-1.211)$ & & 0.746 & \\
\hline Pringle maneuver & & & & & & \\
\hline Yes vs no & $0.886(0.815-0.956)$ & 0.234 & $0.786(0.705-0.898)$ & & 0.846 & \\
\hline Resection type & & & & & & \\
\hline Anatomic vs nonanatomic & $1.366(1.125-1.660)$ & 0.02 & $1.375(1.185-1.595)$ & & $<0.001$ & \\
\hline Resection extent & & & & & & \\
\hline Major vs minor & $1.728(1.422-2.099)$ & $<0.001$ & $1.702(1.468-1.974)$ & & $<0.001$ & \\
\hline Blood loss, ml & & & & & & \\
\hline$>800$ vs $\leq 800$ & $2.217(1.807-2.720)$ & $<0.001$ & $1.761(1.494-2.075)$ & $<0.001$ & & \\
\hline
\end{tabular}


Table 3 Risk factors associated with postoperative disease free survival and overall survival identified by univariate Cox regression analysis in the entire cohort (Continued)

\begin{tabular}{llll}
\hline Variables & \multicolumn{2}{l}{ Univariate Analysis } & \\
\cline { 2 - 3 } & Overall survival & Disease-free survival \\
\cline { 2 - 3 } & Hazard ratio & H-valule & Hazard ratio \\
\hline Yes vs no & $2.107(1.726-2.571)$ & $<0.001$ & p-value \\
\hline
\end{tabular}

Abbreviation: $H B s A g$ hepatitis B virus surface antigen, $A L T$ anlanine transaminase, $N L R$ indicates neutrophil to lymphocyte ratio, $P L R$ platelet to lymphocyte ratio, $A P R I$ alanine transaminase to platelet ratio index, AFP alpha fetoprotein, MVI microscopic vascular invasion, Macro-VTT macroscopic venous tumor thrombus, including portal vein tumor thrombus and hepatic vein tumor thrombus

Table 4 Risk factors associated with postoperative disease free survival and overall survival identified by multivariate Cox regression analysis

\begin{tabular}{|c|c|c|c|c|}
\hline \multirow[t]{2}{*}{ Variables } & \multicolumn{2}{|l|}{ OS } & \multicolumn{2}{|l|}{ DFS } \\
\hline & HR $(95 \% \mathrm{Cl})$ & $p$-value & HR $(95 \% \mathrm{Cl})$ & $p$-value \\
\hline \multicolumn{5}{|c|}{ The entire cohort $(n=1255)$} \\
\hline Age, $y r, \leq 50$ vs $>50$ & & & $0.800(0.688-0.931)$ & 0.004 \\
\hline Cirrhosis, yes vs no & & & $1.328(1.117-1.578)$ & 0.001 \\
\hline ALBI grade, $2+3$ vs 1 & $1.225(1.005-1.494)$ & 0.044 & & \\
\hline$N L R,>2.3$ vs $\leq 2.3$ & $1.080(1.041-1.121)$ & $<0.001$ & $1.034(1.002-1.068)$ & 0.040 \\
\hline Tumor size, $\mathrm{cm},>5$ vs $\leq 5$ & $1.437(1.077-1.916)$ & 0.014 & $1.311(1.073-1.602)$ & 0.008 \\
\hline Tumor no., multiple vs solitary & $1.489(1.206-1.838)$ & $<0.001$ & $1.583(1.343-1.866)$ & $<0.001$ \\
\hline Macro-VTT, yes vs no & $1.662(1.288-2.143)$ & $<0.001$ & $1.377(1.126-1.685)$ & 0.002 \\
\hline MVl, yes vs no & $1.581(1.262-1.980)$ & $<0.001$ & $1.541(1.298-1.829)$ & $<0.001$ \\
\hline AFP, $\mu \mathrm{g} / \mathrm{L},>400$ vs $\leq 400$ & $1.412(1.154-1.726)$ & 0.001 & $1.267(1.086-1.477)$ & 0.003 \\
\hline PBT, yes vs no & $1.623(1.312-2.008)$ & $<0.001$ & $1.365(1.158-1.608)$ & $<0.001$ \\
\hline \multicolumn{5}{|l|}{ BCLC 0-A subgroup $(n=804)$} \\
\hline Age, $y r, \leq 50$ vs $>50$ & & & $0.986(0.977-0.994)$ & 0.001 \\
\hline Cirrhosis, yes vs no & & & $1.325(1.053-1.668)$ & 0.016 \\
\hline ALBI grade, $2+3$ vs 1 & $1.434(1.094-1.879)$ & 0.009 & & \\
\hline$N L R,>2.3$ vs $\leq 2.3$ & $1.105(1.056-1.157)$ & $<0.001$ & $1.054(1.010-1.099)$ & 0.016 \\
\hline MVl, yes vs no & $1.643(1.217-2.220)$ & 0.001 & $1.578(1.252-1.988)$ & $<0.001$ \\
\hline AFP, $\mu \mathrm{g} / \mathrm{L},>400$ vs $\leq 400$ & $1.832(1.390-2.413)$ & $<0.001$ & $1.445(1.167-1.789)$ & 0.001 \\
\hline PBT, yes vs no & $1.756(1.302-2.368)$ & $<0.001$ & $1.607(1.272-2.031)$ & $<0.001$ \\
\hline \multicolumn{5}{|l|}{$B C L C B-C$ subgroup $(n=451)$} \\
\hline Age, yr, $\leq 50$ vs $>50$ & & & $0.989(0.980-0.999)$ & 0.025 \\
\hline Tumor size, $\mathrm{cm},>5$ vs $\leq 5$ & & & $1.826(1.151-2.897)$ & 0.011 \\
\hline Tumor no., multiple vs solitary & $1.546(1.129-2.116)$ & 0.007 & & \\
\hline $\mathrm{PLR},>118.9$ vs $\leq 118.9$ & $1.002(1.000-1.003)$ & 0.013 & & \\
\hline MVl, yes vs no & $1.492(1.059-2.102)$ & 0.022 & $1.568(1.253-1.961)$ & $<0.001$ \\
\hline Macro-VTT, yes vs no & $2.033(1.411-2.929)$ & $<0.001$ & $1.367(1.067-1.752)$ & 0.011 \\
\hline Cirrhosis, yes vs no & & & $1.408(1.083-1.830)$ & 0.014 \\
\hline PBT, yes vs no & $1.257(0.929-1.700)$ & 0.139 & $1.203(0.950-1.525)$ & 0.126 \\
\hline
\end{tabular}

Abbreviation: OS overall survival, DFS disease free survival, $H R$ hazard ratio, 95\% Cl 95\% confident interval, $A B L I$ grade albumin to bilirubin grade, NLR neutrophil to lymphocyte ratio, Macro-VTT macroscopic venous tumor thrombus, MVI microscopic vascular invasion, AFP alpha fetoprotein, PBT perioperative blood transfusion, PLR platelet to lymphocyte ratio 
univariable analysis showed that both blood loss and PBT were significant risk factors of DFS and OS (Table 3). However, it was PBT rather than blood loss affecting both DFS and OS in multivariable analysis (Table 4). Therefore, we believed although blood loss was not adjusted as a selected factor for propensity matching, it would not potentially affect the survival results derived from the matched cohort.

After propensity matching, the baselines of patients with $\mathrm{PBT}$ and those without $\mathrm{PBT}$ were comparable (Table 2) within the BCLC 0-A subset or the BCLC B-C subset. The survival results showed that $\mathrm{PBT}$ significantly reduced postoperative DFS and OS of HCC patients with BCLC stage 0-A (Fig. 2a, b), but it no longer influence the postsurgical survival outcomes of those with BCLC stage B-C (Fig. 2c, d). These were consistent with an early study reported by Ashara et al. in 1999, but our study had superiority in patient number and statistical power. In that study, only 175 patients were included and PSM was not applied to control patient bias [36].

$27.6 \%$ patients required blood transfusion in the entire cohort, but they all achieved curative resection (complete resection of gross tumors with a pathological tumor free margin). Therefore, the volume of intraoperative blood loss does not correlate with the curativity of resection for HCC. To further evaluate the impact of PBT on survival outcomes of HCC, Cox univariable and multivariable regression analyses were performed in the matched cohort. The results showed that PBT, but not blood loss was associated with a reduced DFS and OS (Table 4). PBT was significantly associated with increased risks of poor DFS and OS for the subset of patients with BCLC stage 0-A HCC. However, in the BCLC B-C subset, PBT was not a risk factor affecting DFS and OS. Tumor-related factors (multiple tumor, size, venous tumor thrombus, MVI) are the major risk factors associated with tumor recurrence and OS. In the subset with early tumor, patients with PBT had a shorter DFS or OS may partially result from transfusion-related immunomodulation (TRIM) [37]. Residual leukocyte or apoptotic cells in the stored RBCs may stimulate TGF $\beta$ and TNFa production, which in turn suppresses NK cells and activate Treg cells. Furthermore, microparticles derived from RBCs may contribute to neutrophil priming and activation and promotion of inflammation. These collectively caused immunosuppression [38], thereby promoting tumor recurrence.

This study had several limitations. First, it was a retrospective cohort study, not an RCT trial. However, the large sample size and the combination of PSM (full inclusion of variables and appropriate calipers) and Cox regression analyses strengthened the statistical data, thereby yielding reliable results. Second, it was a single- center study, and most patients had hepatitis B virusrelated HCC. External validation by other independent cohorts with different HCC etiologies is needed.

\section{Conclusions}

The present study demonstrated that PBT would significantly reduce DFS and OS of patients with BCLC stage 0-A HCC, but not those of patients with BCLC stage BC HCC after curative liver resection. Deliberate preoperative planning and refined intraoperative manipulation are required to minimize blood loss and transfusion, thereby improving outcomes of HCC.

\section{Abbreviations}

AFP: Alpha fetal protein; ALBI: Albumin to bilirubin; APRI: Alanine transaminase -to-platelet ratio index; ALT: Alanine transaminase; AR: Anatomical resection; BCLC: Barcelona Clinic Liver Cancer; 95\% Cl: 95\% confidence interval; DFS: Disease free survival; HCC: Hepatocellular carcinoma; HR: Hazard ratio; HVTT: Hepatic vein tumor thrombus; MVI: Microscopic vascular invasion; NAR: Non-anatomical resection; NLR: Neutrophil to lymphocyte ratio; OS: Overall survival; PBT: Perioperative blood transfusion; PLR: Platelet to lymphocyte ratio; PSM: Propensity score matching; PVIT: Portal vein tumor thrombus

\section{Acknowledgements}

We thank Prof. Fu-Tian Luo from the Department of Statistics of Sun Yat-sen University for his statistic analysis.

\section{Authors' contributions}

Study design, conception, manuscript drafting and revision: SQL, GXC. Data collection, acquisition and analysis: GXC, CYQ, WJH, XHH, YPH. Administrative support and manuscript review: MK, BGP and LJL. Final approval of manuscript: all authors.

\section{Funding}

This work was supported by a grant from the National Natural Science Foundation of China (No. 81472254), Science and Technology Planning Project of Guangdong Province, China (No. 2016A020215064). The funding sources were not involved in the design of this study, in the collection, analysis, and interpretation of the data, or in writing of the manuscript.

\section{Availability of data and materials}

All data generated or analysed during this study are included in this published article.

\section{Ethics approval and consent to participate}

This study was approved by the Ethics Committee of The First Affiliated Hospital of Sun Yat-sen University, and written informed consent was obtained from all patients before treatment.

\section{Competing interests}

The authors declare there is no competing interests.

\section{Author details}

${ }^{1}$ Department of Liver Surgery, The First Affiliated Hospital of Sun Yat-sen University, No. 58 Zhongshan Er Road, Guangzhou 510080, China.

${ }^{2}$ Department of Operating Center, The First Affiliated Hospital of Sun Yat-sen University, No. 58 Zhongshan Er Road, Guangzhou 510080, China.

Received: 29 March 2019 Accepted: 20 May 2020

Published online: 29 May 2020

\section{References}

1. Chen W, Zheng R, Baade PD, Zhang S, Zeng H, Bray F, et al. Cancer statistics in China, 2015. CA Cancer J Clin. 2016:66:115-32.

2. European Association for the Study of the Liver; European Organization for Research and Treatment of Cancer. EASL-EORTC clinical practice guidelines: management of hepatocellular carcinoma. J Hepatol. 2012;56:908-43. 
3. Fan ST, Mau Lo C, Poon RT, Yeung C, Leung LC, Yuen WK, et al. Continuous improvement of survival outcomes of resection of hepatocellular carcinoma: a 20-year experience. Ann Surg. 2011;253:745-58.

4. Lim KC, Chow PK, Allen JC, Siddiqui FJ, Chan ES, Tan SB. Systematic review of outcomes of liver resection for early hepatocellular carcinoma within the Milan criteria. Br J Surg. 2012;99:1622-9.

5. Cescon M, Vetrone G, Grazi GL, Ramacciato G, Ercolani G, et al. Trends in perioperative outcome after hepatic resection: analysis of 1500 consecutive unselected cases over 20 years. Ann Surg. 2009;249:995-1002.

6. Carlos M, Caveh M, Donat RS. Allogeneic blood transfusions: benefit, risks and clinical indications in countries with a low or high human development index. Br Med Bull. 2004;70:15-28.

7. Kuroda S, Tashiro H, Kobayashi T, Oshita A, Amano H, Ohdan H. No impact of perioperative blood transfusion on recurrence of hepatocellular carcinoma after hepatectomy. World J Surg. 2012;36:651-8.

8. Peng $T$, Zhao G, Wang L, Wu J, Cui H, Liang $Y$, et al. No impact of perioperative blood transfusion on prognosis after curative resection for hepatocellular carcinoma: a propensity score matching analysis. Clin Trans Oncol. 2018;20:719-28.

9. Yang T, Lu JH, Lau WY, Zhang TY, Zhang H, Shen YN, et al. Perioperative blood transfusion does not influence recurrence-free and overall survivals after curative resection for hepatocellular carcinoma. J Hepatol. 2016;64: 583-93.

10. Harada N, Shirabe K, Maeda T, Kayashima H, Ishida T, Maehara Y. Blood transfusion is associated with recurrence of hepatocellular carcinoma after hepatectomy in child-Pugh class a patients. World J Surg. 2015;39:1044-51.

11. Wada H, Eguchi $H$, Nagano H, Kubo S, Nakai T, Kaibori M, et al. Perioperative allogenic blood transfusion is a poor prognostic factor after hepatocellular carcinoma surgery: a multi-center analysis. Surg Today. 2018;48:73-9.

12. Liu L, Wang Z, Jiang S, Shao B, Liu J, Zhang S, et al. Perioperative allogenenic blood transfusion is associated with worse clinical outcomes for hepatocellular carcinoma: a meta-analysis. PLoS One. 2013;8:e64261.

13. Li SQ, Huang T, Shen SL, Hua YP, Hu WJ, Kuang M, et al. Anatomical versus non-anatomical liver resection for hepatocellular carcinoma exceeding Milan criteria. Br J Surg. 2017;104:118-27.

14. Bruix J, Reig M, Sherman M. Evidence-based diagnosis, staging, and treatment of patients with hepatocellular carcinoma. Gastroenterology. 2016;150:835-53.

15. Johnson PJ, Berhane S, Kagebayashi C, Satomura S, Teng M, Reeves HL, et al. Assessment of liver function in patients with hepatocellular carcinoma: a new evidence-based approach — the ALBI grade. J Clin Oncol. 2015;33: 550-8.

16. Pinato DJ, Sharma R, Allara E, Yen C, Arizumi T, Kubota K, et al. The ALBI grade provides objective hepatic reserve estimation across each $B C L C$ stage of hepatocellular carcinoma. J Hepatol. 2017:66:338-46.

17. Clavien PA, Barkun J, de Oliveira ML, Vauthey JN, Dindo D, Schulick RD, et al. The Clavien-Dindo classification of surgical complications: five-year experience. Ann Surg. 2009;250:187-96.

18. Rubin DB, Thomas N. Matching using estimated propensity score: relating theory to practice. Biometrics. 1996;52:249-64.

19. Stuart EA. Matching methods for causal inference: a review and a look forward. Stat Sci. 2010;25:1-21.

20. Margonis GA, Sasaki K, Andreatos N, Nishioka Y, Sugawara T, Amini N, et al. Prognostic impact of complications after resection of early stage hepatocellular carcinoma. J Surg Oncol. 2017;115:791-804.

21. You DD, Kim DG, Seo CH, Choi HJ, Yoo YK, Park YG. Prognostic factors after curative resection hepatocellular carcinoma and the surgeon's role. Ann Surg Treat Res. 2017;93:252-9.

22. Makino Y, Yamanoi A, Kimoto T, El-Assal ON, Kohno H, Nagasue N. The influence of perioperative blood transfusion on intrahepatic recurrence after curative resection of hepatocellular carcinoma. Am J Gastroenterol. 2000;95: 1294-300.

23. Yamamoto J, Kosuge T, Takayama T, Shimada K, Yamasaki S, Ozaki H, et al. Perioperative blood transfusion promotes recurrence of hepatocellular carcinoma after hepatectomy. Surgery. 1994;115:303-9.

24. Shiba H, Ishida Y, Wakiyama S, lida T, Matsumoto M, Sakamoto T, et al. Negative impact of blood transfusion on recurrence and prognosis of hepatocellular carcinoma after hepatic resection. J Gastrointest Surg. 2009; 13:1636-42.

25. Hwang S, Lee YJ, Kim KH, Kim KH, Ahn CS, Moon DB, et al. The impact of tumor size on long-term survival outcomes after resection of solitary hepatocellular carcinoma: single-institution experience with 2558 patients. J Gastrointest Surg. 2015;19:1281-90.

26. Goh BK, Teo JY, Chan CY, Lee SY, Jeyaraj P, Cheow PC, et al. Importance of tumor size as a prognostic factor after partial liver resection for solitary hepatocellular carcinoma: implications on the current AJCC staging system. J Surg Oncol. 2016;113:89-93.

27. Sumie S, Nakashima O, Okuda K, Kuromatsu R, Kawaguchi A, Nakano M, et al. The significance of classifying microvascular invasion in patients with hepatocellular carcinoma. Ann Surg Oncol. 2014;21:1002-9.

28. Yang SL, Liu LP, Yang S, Liu L, Ren JW, Fang X, et al. Preoperative serum afetoprotein and prognosis after hepatectomy for hepatocellular carcinoma. Br J Surg. 2016;103:716-24

29. Okamura Y, Sugiura T, Ito T, Yamamoto Y, Ashida R, Mori K, et al. Neutrophil to lymphocyte ratio as an indicator of the malignant behaviour of hepatocellular carcinoma. Br J Surg. 2016;103:891-8.

30. Yang T, Zhu J, Zhao L, Mai K, Ye J, Huang S, et al. Lymphocye to monocyte ratio and neutrophil to lymphocyte ratio are superior inflammation-based predictors of recurrence in patients with hepatocellular carcinoma after hepatic resection. J Surg Oncol. 2016;115:718-28.

31. Shen SL, Fu SJ, Chen B, Kuang M, Li SQ, Hua YP, et al. Preoperative aspartate aminotransferase to platelet ratio is an independent prognostic factor for hepatitis B-induced hepatocellular carcinoma after hepatic resection. Ann Surg Oncol. 2014;21:3802-9.

32. D'Agostino RB Jr. Propensity score methods for bias reduction in the comparison of a treatment to a non-randomized control group. Stat Med. 1998;17:2265-81.

33. Brookhart MA, Schneeweiss S, Rothman KJ, Glynn RJ, Til ST. Variable selection for propensity score models. Am J Epidemiol. 2006;163:1149-56.

34. Ali MS, Groenwold RH, Belitser SV, Pestman WR, Hoes AW, Roes KCB, et al. Reporting of covariate selection and balance assessment in propensity score analysis is suboptimal: a systematic review. J Clin Epidemiol. 2015;68: 122-31.

35. Katz SC, Shia J, Liau KH, Gonen M, Ruo L, Jarnagin WR, et al. Operative blood loss independently predicts recurrence and survival after resection of hepatocellular carcinoma. Ann Surg. 2009;249:617-23.

36. Asahara T, Katayama K, Itamoto T, Yano M, Hino H, Okamoto Y, et al. Perioperative blood transfusion as a prognostic indicator in patients with hepatocellular carcinoma. World J Surg. 1999;23:676-80.

37. Goubran H, Sheridan D, Radosevic J, Burnouf T, Seghatchian J. Transfusionrelated immunomodulation and cancer. Transfus Apheresis Sci. 2017. https://doi.org/10.1016/j.transci.2017.05.019.

38. Remy KE, Hall MW MW, Cholette J, Juffermans NP, Kathleen Nicol K, Doctor A, et al. Mechanisms of red blood cell transfusion-related immunomodulation. Transfusion. 2018:58:804-15.

\section{Publisher's Note}

Springer Nature remains neutral with regard to jurisdictional claims in published maps and institutional affiliations.

\section{Ready to submit your research? Choose BMC and benefit from:}

- fast, convenient online submission

- thorough peer review by experienced researchers in your field

- rapid publication on acceptance

- support for research data, including large and complex data types

- gold Open Access which fosters wider collaboration and increased citations

- maximum visibility for your research: over $100 \mathrm{M}$ website views per year

At $\mathrm{BMC}$, research is always in progress.

Learn more biomedcentral.com/submission 